\title{
The basic difference in the pharmacological spectrum between methamphetamine and its derivative, the enhancer substance (-)-deprenyl Ildikó Miklya
}

Address: Department of Pharmacology and Pharmacotherapy, Semmelweis University, Budapest, Hungary

Email: Ildikó Miklya - mikild@hotmail.com

from I3th Scientific Symposium of the Austrian Pharmacological Society (APHAR). Joint Meeting with the Austrian Society of Toxicology (ASTOX) and the Hungarian Society for Experimental and Clinical Pharmacology (MFT)

Vienna, Austria. 22-24 November 2007

Published: 14 November 2007

BMC Pharmacology 2007, 7(Suppl 2):A33 doi:10.1186/147I-2210-7-S2-A33

This abstract is available from: http://www.biomedcentral.com/I47I-22I0/7/S2/A33

(c) 2007 Miklya; licensee BioMed Central Ltd.

Beta-phenylethylamine (PEA), the parent compound of both methamphetamine and (-)-deprenyl, has two effects: it is a releaser of catecholamines and a natural enhancer substance. Methamphetamine, the closest mother compound of (-)-deprenyl, acts like PEA. (-)-Deprenyl was the first PEA derivative which lost the releasing property but preserved the enhancer effect. We elaborated a method on isolated rat brain stem, which allowed to measure the enhancer effect of (-)-deprenyl and to detect how the releasing effect of methamphetamine hinders the recognition of its enhancer effect. We fill up the intraneuronal transmitter stores of the noradrenergic neurons in an isolated rat brain stem with $\left[{ }^{3} \mathrm{H}\right]$ noradrenaline and thereafter continuously measure the amount of the labeled transmitter released from the organ. Electrical stimulation increases the amount of $\left[{ }^{3} \mathrm{H}\right]$ noradrenaline released into the bathing fluid. Due to its enhancer effect, $2 \mu \mathrm{g} / \mathrm{ml}(-)$ deprenyl significantly increases the amount of labeled transmitter to the same stimulation. The addition of $2 \mu \mathrm{g} /$ $\mathrm{ml}$ amphetamine or methamphetamine to the bathing fluid in the resting state rapidly leads to the continuous release of a high amount of $\left[{ }^{3} \mathrm{H}\right]$ noradrenaline into the organ bath and electrical stimulation is unable to further increase the amount of the labeled transmitter, thus hindering the detectability of the enhancer effect.

\section{Acknowledgements}

This work was supported by the Health Scientific Council (ETT I40/2003, ETT 606/2006). 